\title{
PENGARUH CUSTOMER SATISFACTION, PERCEIVED VALUE, DAN TRUST TERHADAP ONLINE REPURCHASE INTENTION PADA FASHION DI INSTAGRAM DI JAKARTA
}

\author{
Florensia Aurelia dan Muhammad Tony Nawawi \\ Program Studi Manajemen Fakultas Ekonomi dan Bisnis, Universitas Tarumanagara, Jakarta \\ ${ }^{1}$ Email : Florensia.115160370@stu.untar.ac.id
}

\begin{abstract}
The fast growing internet has resulted in competitive businesses, namely providing opportunities and challenges for various businesses. One of these business opportunities is to do business online. Online transaction systems require customers to buy and make payments for products and services using internet platforms such as social media. The purpose of this study was to study the effect of customer satisfaction, perceived value, and trust in online repuchase intentions on Instagram. Data was collected by survey questionnaire. This study collected 115 valid responses from Instagram users who must have made an online purchase before at least once. SmartPLS 3.0 is used for approved approved studies. The results show that (1) There is a significant positive effect on customer satisfaction with online repurchase intentions. (2) There is a significant positive effect of perceived value on online repurchase intentions. (3) There is a significant positive effect of trust on online repurchase intentions.
\end{abstract}

Keywords: customer satisfaction, perceived value, trust, online repurchase intention.

Abstrak: Internet yang cepat berkembang telah menciptakan bisnis yang kompetitif, yaitu memberikan peluang dan tantangan untuk berbagai bisnis. Salah satu peluang bisnis ini adalah dengan melakukan bisnis online. Sistem transaksi online meminta pelanggan untuk membeli dan melakukan pembayaran untuk produk dan layanan menggunakan platform internet seperti sosial media. Tujuan dari penelitian ini adalah untuk mengetahui pengaruh customer satisfaction, perceived value, dan trust terhadap online repuchase intention pada fashion di Instagram. Data dikumpulkan dengan membagikan kuesioner survei. Penelitian ini mengumpulkan 115 tanggapan valid dari pengguna Instagram yang pasti pernah melakukan pembelian online sebelumnya minimal satu kali. SmartPLS 3.0 digunakan untuk memverifikasi kerangka penelitian. Hasil menunjukkan bahwa (1) terdapat pengaruh positif yang signifikan customer satisfaction terhadap online repurchase intention. (2) terdapat pengaruh positif yang signifikan perceived value terhadap online repurchase intention. (3) terdapat pengaruh positif yang signifikan trust terhadap online repurchase intention.

Kata kunci: customer satisfaction, perceived value, trust, online repurchase intention. 


\section{LATAR BELAKANG}

Perkembangan zaman yang sangat pesat juga membuat perekonomian Indonesia ikut berubah dan berpengaruh kepada masyarakat, perusahaan, beserta pasarnya. Ekonomi makro memiliki peran penting dalam sebuah bisnis dan juga mampu mempengaruhi pertumbuhan ekonomi, stabilitas harga, tenaga kerja, dan pencapaian keseimbangan. Permasalahan ekonomi makro yang terjadi pada bisnis seperti, kemiskinan, pengangguran, krisis nilai tukar terhadap luar negeri, pertumbuhan ekonomi, dan lain-lain, sehingga muncul bisnis online sebagai sektor perekonomian yang baru.

Pada era globalisasi sekarang ini persaingan dalam dunia bisnis sangat ketat. Perusahaan berlomba-lomba bersaing untuk mempertahankan bisnis mereka agar tetap dapat bertahan di tengah persaingan. Perusahaan yang semula menerapkan bisnis secara offline, sekarang mulai merambah ke bisnis online. Dengan adanya perkembangan teknologi dan informasi khususnya internet, mempermudah suatu perusahaan untuk menciptakan pelanggan baru dan mempertahankan pelanggan lama karena internet dapat memiliki koneksi dan jangkauan yang sangat luas. Oleh karena itu internet adalah salah satu kebutuhan pokok bagi sebagian besar orang selain kebutuhan pangan, sandang, dan papan. Penggunaan internet yang semakin meningkat tentu akan menjadi sebuah peluang usaha bisnis baru dengan menyediakan toko online khususnya di media sosial.

Media sosial menjadi trend yang berkembang dan menciptakan peluang bagi perusahaan atau perorangan untuk tetap kompetitif dengan menyediakan pelanggan dengan cara yang nyaman, lebih cepat dan lebih murah untuk melakukan pembelian. Menurut Grunert and Ramus (2005) di nyatakan bahwa pembelian melalui internet merupakan salah satu sarana bentuk belanja yang paling cepat berkembang di masa modern saat ini. Salah satunya, Instagram merupakan media sosial yang sangat populer. Instagram memberikan kemudahan untuk memasarkan produk agar lebih efektif dan efisien. Adanya Instagram membuat penjual online menampilkan produk secara jelas yang dapat menghasilkan keuntungan serta dapat membina hubungan yang baik antar pelanggan.

Pada saat ini produk yang paling banyak di jual pada toko online di Instagram adalah produk fashion, karena fashion di Indonesia semakin berkembang akibat dari adanya modernisasi. Akibat perkembangan ini masyarakat menjadi selektif dalam menentukan gaya hidup. Hubungan antara gaya hidup dengan fashion sangat erat, karena fashion akan menjadikan seseorang menjadi lebih menarik. Oleh karena itu, produk fashion merupakan salah satu produk yang paling laris dijual pada toko online dan dibeli kembali oleh pelanggan terutama pada fashion pakaian. Pada dasarnya, ketika pelanggan mendapatkan kepuasan, nilai dari produk tersebut dan kepercayaan yang diberikan, pelanggan cenderung akan melakukan pembelian kemnbali pada toko online tersebut.

Menurut Hellier et al. (2003) mengenai repurchase intention dinyatakan bahwa keputusan seseorang untuk melakukan pembelian kembali atas produk atau jasa, dengan mempertimbangkan situasi yang terjadi dan tingkat kesukaan. Menurut Reichheld \& Schefter (2000), pada dasarnya bahwa penjual online harus memiliki pemahaman tentang faktor-faktor yang dapat memengaruhi pelanggan untuk mempertahankan hubungan jangka panjang dengan penjual. 
Penelitian ini relevan dengan penelitian yang dilakukan oleh Nguyen Ngoc Duy Phuong, and Tran Thi Dai Trang (2018) bahwa kepuasan pelanggan berpengaruh positif yang signifikan terhadap niat pembelian kembali. Penelitian Chai Har Lee, Uchenna Cyril Eze, Nelson Oly Ndubisi (2011) juga mengatakan bahwa perceived value dan trust berpengaruh positif yang signifikan terhadap niat pembelian kembali online (online repurchase intention). Penelitian ini dilakukan untuk mengetahui apakah customer satisfaction, perceived value, dan trust dapat mempengaruhi online repurchase intention pada fashion di instagram di Jakarta.

Tujuan penelitian ini adalah untuk menguji apakah customer satisfaction, perceived value, dan trust dapat mempengaruhi secara positif dan signifikan online repurchase intention. Diharapkan penelitian ini dapat bermanfaat bagi perusahaan sebagai dasar pengambilan keputusan untuk menentukan langkah-langkah dimasa yang akan datang terkait dengan variabel-variabel diteliti yang memberikan pengaruh signifikan terhadap online repurchase intention.

\section{KAJIAN TEORI}

Menurut Chiu et al. (2012,p.835), "Online repurchase intention is subjective probability that experienced shoppers will make purchase again from same online retailer". Selain itu, menurut Hellier, Geursen, Carr dan Rickard (2003,p.1764), "Online repurchase intention is the individual's decision about buying again a designated service from the same company, taking into accounts his or her present situation and likely circumstances". Berdasarkan definisi di atas, dapat disimpulkan bahwa online repurchase intention adalah niat pelanggan untuk membeli kembali suatu produk yang di tawarkan oleh toko online setelah pelanggan tersebut mendapatkan pengalaman positif terhadap produk yang di terima.

Menurut Chiu et al. (2009,p.351), "Satisfaction is an evaluation and emotional response to the online shopping experience". Selain itu, menurut Zhao (2010,p.48), "Defined satisfaction is in terms of a pleasing psychological experience in response to an online purchase". Begitu juga menurut Cronin et al (2000,p.200) "Customer satisfaction is as an evaluation of emotions reflecting the degree to which the customer believes the service provider evokes positive feelings". Berdasarkan definisi di atas, dapat disimpulkan bahwa customer satisfaction adalah perasaan pelanggan (bisa baik atau buruk) sebagai suatu respon afektif dan emosional pelanggan yang muncul dari benak pelanggan setelah merasakan pengalaman layanan suatu pengecer online.

Menurut Kotler (2008,p.83), "Customer perceived value is the difference between the perspective customer's evaluation of all benefits and all the costs of an offering and the perceived alternatives". Selain itu, menurut Zeithaml (2000,p.78), "Perceived value is as the consumer's overall assessment of the utility of a product based on perceptions of what is received and what is given". Berdasarkan definisi di atas, dapat disimpulkan bahwa perceived value adalah perbandingan semua evaluasi pelanggan atas keuntungan (manfaat) dan biaya yang dikeluarkan dari berbagai perspektif pelanggan (produk layak dibeli atau tidak). Setelah mereka merasakan langsung produk dari toko online tersebut, dimana nanti perceived value muncul karena apa yang telah dibayarkan sesuai dengan apa yang didapat (manfaat). 
Pavlou dan Fygenson (2006,p.123) mendefinisikan, "Trust is defined as the buyer's belief that the e-vendor is behaving ethically". Menurut Gefen, Karahanna, \& Straub (2003,p.62), "Defines trust is a set of specific relationship intentions dealing primarily with integrity, benevolence, competence, and predictability of an Internet online retailer". Demikian juga, menurut Chen (2010,p.309), "Defined trust is a willingness to depend on one object based on the belief or expectation resulting from its credibility, benevolence, and ability about environmental performance". Berdasarkan definisi di atas, dapat disimpulkan bahwa trust adalah semua keyakinan yang di miliki pelanggan bahwa penjual mempunyai perilaku yang etis, terutama berhubungan dengan integritas, moral, sikap, yang diberikan oleh penjual online.

Model penelitian yang digunakan dalam penelitian ini digambarkan sebagai berikut:

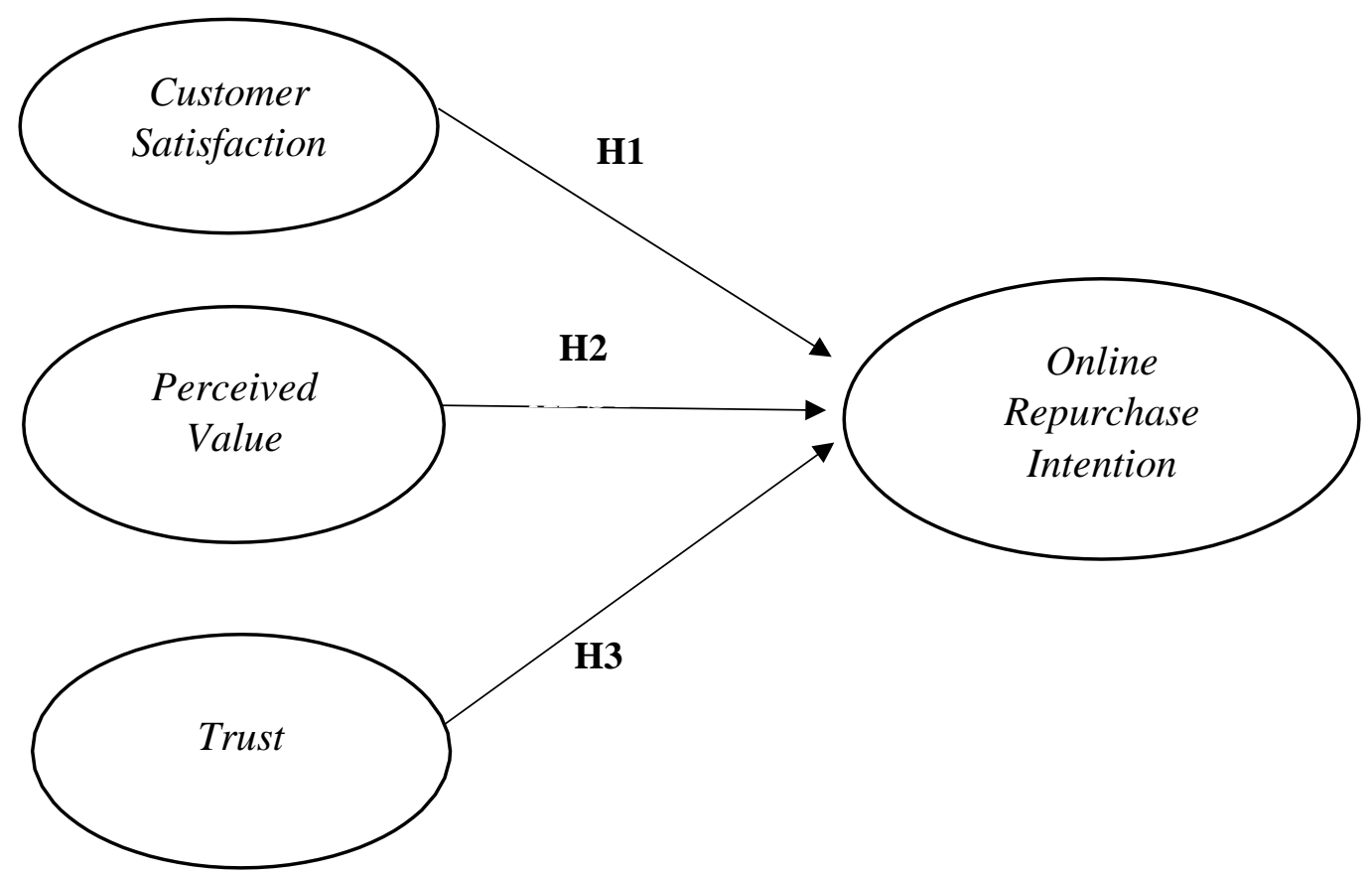

Gambar 1. Model Penelitian

Berdasarkan gambar diatas dapat dirumuskan hipotesis untuk penelitian sebagai berikut:

$\mathrm{H}_{1}$ : Terdapat pengaruh positif yang signifikan customer satisfaction terhadap online repurchase intention.

$\mathrm{H}_{2}$ : Terdapat pengaruh positif yang signifikan perceived value terhadap online repurchase intention.

$\mathrm{H}_{3}$ : Terdapat pengaruh positif yang signifikan trust terhadap online repurchase intention.

\section{METODOLOGI}

Desain penelitian yang digunakan dalam penelitian ini adalah desain deskriptif dengan menggunakan cross-sectional designs, karena desain penelitian ini digunakan untuk menjawab permasalahan yang sedang terjadi pada situasi sekarang dan penelitian ini tidak dilaksanakan eksperimen lebih lanjut serta tidak ada variabel yang dimanipulasi, artinya 
bahwa data dikumpulkan dari suatu sampel adalah data yang sebenarnya dan penelitian ini dilakukan hanya satu kali dan informasi yang diperoleh juga satu kali. Sampel yang digunakan dalam penelitian ini adalah pengguna instagram yang sudah pernah berbelanja online pada toko online tersebut minimal satu kali atau lebih dari satu kali sebelumnya dengan menggunakan teknik pemilihan sampel secara convenience. Pengambilan sampel dilakukan dengan menyebarkan kuesioner secara online menggunakan google forms. Responden yang berhasil dikumpulkan sebanyak 115 responden pengguna instagram yang sudah pernah berbelanja online pada toko online tersebut minimal satu kali atau lebih dari satu kali sebelumnya.

\section{HASIL UJI STATISTIK}

Pada penelitian ini, berdasarkan 115 responden, mayoritas responden adalah berjenis kelamin wanita $(66,1 \%)$, berusia $21-30$ tahun $(80 \%)$, berpendidikan terakhir SMA $(71,3 \%)$. Responden menggunakan media elektonik untuk mengakses aplikasi instagram yaitu smartphone (93\%), seluruh responden telah melakukan pembelian minimal 1 kali dalam 1 bulan $(49,6 \%)$, dan durasi responden mengakses instagram dalam satu hari yaitu $>5 \mathrm{jam} / \mathrm{hari}$ $(53,9 \%)$.

Pada penelitian ini, variabel diukur menggunakan skala likert dengan bobot sebanyak 5 poin. Angka 1 menunjukkan sangat tidak setuju (STS) dan angka 5 menunjukkan sangat setuju (SS). Kemudian dilakukan analisis validitas dan reliabilitas dan dimodifikasi, sehingga tersisa 15 item dari 17 item karena jika nilai loading faktor $<0,70$ dan nilai AVE $<0,50$ maka dianggap tidak valid (Ghozali, 2014,p.74) dan harus dihapus dari model penelitian. Setelah dimodifikasi hasil menunjukkan nilai loading faktor $>0,70$ dan nilai AVE > 0,50 yang artinya bahwa convergent validity telah valid dan begitu juga dengan nilai cross-loadings pada discriminant validity. Pada hasil uji reliabilitas semua nilai composite reliability $>0,70$ yang artinya bahwa pengujian dinyatakan valid atau mempunyai reliabilitas yang tinggi (Ghozali, 2014,p.75).

Tabel 1

Average Variance Extracted (AVE)

\begin{tabular}{|c|c|c|c|}
\hline & Model Awal & Modifikasi & Keterangan \\
\hline X1 & 0,655 & 0,655 & Valid \\
\hline X2 & $\mathbf{0 , 4 9 5}$ & 0,715 & Valid \\
\hline X3 & 0,607 & 0,607 & Valid \\
\hline Y & 0,686 & 0,686 & Valid \\
\hline
\end{tabular}

Sumber : Hasil pengolahan data dengan SmartPLS 3.0 
Tabel 2

Hasil Nilai Outer Loadings

\begin{tabular}{|c|c|c|c|c|}
\hline & & Model awal & Modifikasi & Keterangan \\
\hline & CS1 & 0,734 & 0,734 & Valid \\
\hline & $\mathrm{CS} 2$ & 0,817 & 0,817 & Valid \\
\hline & $\mathrm{CS} 3$ & 0,837 & 0,837 & Valid \\
\hline & $\mathrm{CS} 4$ & 0,844 & 0,844 & Valid \\
\hline & PV1 & 0,643 & & \\
\hline & PV2 & 0,795 & 0,841 & Valid \\
\hline PV3 & 0,819 & 0,850 & Valid & \\
\hline PV4 & 0,784 & 0,845 & Valid & \\
\hline PV5 & 0,377 & & & \\
\hline TR1 & 0,793 & 0,793 & Valid & \\
\hline TR2 & 0,804 & 0,804 & Valid & \\
\hline TR3 & 0,731 & 0,731 & Valid & \\
\hline TR4 & 0,786 & 0,786 & Valid & \\
\hline ORI1 & 0,847 & 0,848 & Valid & \\
\hline ORI2 & 0,799 & 0,798 & Valid & \\
\hline ORI3 & 0,829 & 0,829 & Valid & \\
\hline ORI4 & 0,837 & 0,837 & Valid & \\
\hline
\end{tabular}

Sumber : Hasil pengolahan data dengan SmartPLS 3.0

Tabel 3

Uji Composite Reliability

\begin{tabular}{|c|c|c|}
\hline Variabel & Composite Reliability & Keterangan \\
\hline Customer Satisfaction (X1) & 0,883 & Reliabel \\
\hline Perceived Value (X2) & 0,883 & Reliabel \\
\hline Trust (X3) & 0,861 & Reliabel \\
\hline Online Repurchase Intention (Y) & 0,897 & Reliabel \\
\hline
\end{tabular}

Sumber : Hasil pengolahan data dengan SmartPLS 3.0

Ketepatan model diukur melalui hubungan koefisien determinasi $\left(\mathrm{R}^{2}\right)$. Berikut adalah hasil estimasi nilai $\mathrm{R}^{2}$ dengan menggunakan SmartPls.

Tabel 4

Hasil Nilai $\mathbf{R}^{2}$

\begin{tabular}{|l|l|l|}
\hline \multicolumn{1}{|c|}{ Variabel } & \multicolumn{1}{|c|}{ R-square } & R-square Adjusted \\
\hline Y (Online Repurchase Intention) & 0,640 & 0,630 \\
\hline
\end{tabular}

Sumber : Hasil pengolahan data dengan Smart PLS 3.0

Pada tabel diatas menunjukkan nilai $R$-square yang diperoleh adalah sebesar 0,630. Sehingga, variabel online repurchase intention dipengaruh sebesar $63 \%$ oleh customer satisfaction (CS), perceived value (PV), dan trust (TR). Hal ini dapat di simpulkan bahwa 
pengaruh model variabel independen terhadap variabel dependen adalah pengaruh yang kuat atau ketepatan model kuat.

Tabel 5
Hasil Pengujian Predictive Relevance $\left(\mathbf{Q}^{\mathbf{2}}\right)$
\begin{tabular}{|c|c|}
\hline Variabel & Predictive Relevance $\left(\boldsymbol{Q}^{\mathbf{2}}\right)$ \\
\hline Online Repurchase Intention $(\mathrm{Y})$ & 0,407 \\
\hline
\end{tabular}

Sumber : Hasil pengolahan data dengan SmartPLS 3.0

Berdasarkan hasil tabel 4.13 diatas, menunjukkan nilai predictive relevance $\left(\mathrm{Q}^{2}\right)$ yang diperoleh adalah sebesar 0,407. Sehingga dapat disimpulkan bahwa, nilai observasi yang dihasilkan oleh variabel atau model adalah baik dan memiliki predictive relevance karena nilai $\mathrm{Q}^{2}$ lebih besar dari $0\left(\mathrm{Q}^{2}>0\right)$.

Hasil perhitungan nilai GoF dilakukan secara manual dengan rumus:

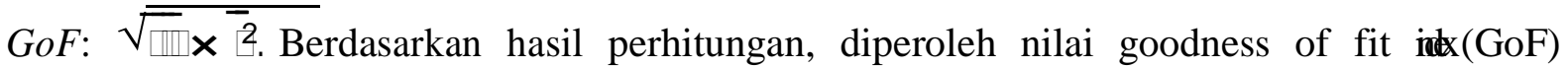
adalah sebesar 0,648. Sehingga dapat disimpulkan bahwa model yang digunakan pada penelitian mempunyai kecocokan baik model penelitian dan termasuk kedalam tingkat goodness of fit index $(\mathrm{GoF})$ yang besar.

Pengujian hipotesis pada penelitian ini dilakukan dengan melihat besarnya nilai $t$ statistic dan nilai p-value yang terdapat pada masing-masing variabel untuk menentukan tingkat signifikansinya.

\section{Tabel 6}

Hasil Pengujian Hipotesis

\begin{tabular}{|c|c|c|c|c|c|}
\hline & Hipotesis & $\begin{array}{c}\text { Original } \\
\text { Sample }\end{array}$ & T-statistik & P-value & Kesimpulan \\
\hline H1 & $\begin{array}{c}\text { Customer Satisfaction } \rightarrow \text { Online } \\
\text { Repurchase Intention }\end{array}$ & 0,545 & 6,033 & 0,000 & Signifikan \\
\hline H2 & $\begin{array}{c}\text { Perceived Value } \rightarrow \text { Online } \\
\text { Repurchase Intention }\end{array}$ & $-0,151$ & 2,115 & 0,035 & Signifikan \\
\hline H3 & $\begin{array}{c}\text { Trust } \rightarrow \text { Online Repurchase } \\
\text { Intention }\end{array}$ & 0,446 & 5,697 & 0,000 & Signifikan \\
\hline
\end{tabular}

Sumber : Hasil pengolahan data dengan SmartPLS 3.0

Pengujian Hipotesis Customer Satisfaction $\left(\mathrm{X}_{1}\right)$ terhadap Online Repurchase Intention (Y)

Diperoleh hasil pengujian hipotesis di atas dengan melihat besarnya nilai $t$-statistic ( $>$ 1,96) dan nilai $p$-value $(<0,05)$. Pada pengujian hipotesis $\left(\mathrm{H}_{1}\right)$, nilai $t$-statistic sebesar 6,033 dan nilai $p$-value sebesar 0,000 , artinya sudah sesuai dengan kriteria yang diinginkan. Berdasarkan hasil tersebut dapat disimpulkan bahwa $\left(\mathrm{H}_{1}\right)$ diterima, yang artinya terdapat pengaruh positif yang signifikan customer satisfaction terhadap online repurchase intention.

Pengujian Hipotesis Perceived Value $\left(\mathrm{X}_{2}\right)$ terhadap Online Repurchase Intention (Y)

Diperoleh hasil pengujian hipotesis di atas dengan melihat besarnya nilai $t$-statistic ( > $1,96)$ dan nilai $p$-value $(<0,05)$. Pada pengujian hipotesis $\left(\mathrm{H}_{2}\right)$, nilai $t$-statistic sebesar 2,115 
dan nilai $p$-value sebesar 0,035 , artinya sudah sesuai dengan kriteria yang diinginkan. Berdasarkan hasil tersebut dapat disimpulkan bahwa $\left(\mathrm{H}_{1}\right)$ diterima, yang artinya terdapat pengaruh positif yang signifikan perceived value terhadap online repurchase intention

Pengujian Hipotesis Trust terhadap $\left(\mathrm{X}_{3}\right)$ Online Repurchase Intention (Y)

Diperoleh hasil pengujian hipotesis di atas dengan melihat besarnya nilai $t$-statistic ( > 1,96) dan nilai $p$-value $(<0,05)$. Pada pengujian hipotesis $\left(\mathrm{H}_{3}\right)$, nilai $t$-statistic sebesar 5,697 dan nilai $p$-value sebesar 0,000 , artinya sudah sesuai dengan kriteria yang diinginkan. Berdasarkan hasil tersebut dapat disimpulkan bahwa $\left(\mathrm{H}_{3}\right)$ diterima, yang artinya terdapat pengaruh positif yang signifikan trust terhadap online repurchase intention.

\section{DISKUSI}

Customer satisfaction adalah pengaruh positif yang signifikan terhadap online repurchase intention dengan nilai $t$-statistic di atas $1,96(>1,96)$ dan nilai $p$-value di bawah $0,05(<0,05)$. Hasil penelitian ini relevan dengan penelitian yang dilakukan oleh Nguyen Ngoc Duy Phuong, and Tran Thi Dai Trang (2018) bahwa kepuasan pelanggan berpengaruh positif yang signifikan terhadap niat pembelian kembali. Kepuasan pelanggan adalah salah satu faktor penting yang dapat menentukan pelanggan untuk melakukan online repurchase intention atau tidak. Apabila pelanggan merasa puas pada produk yang dibeli, maka kecendrungan pelanggan untuk setia terhadap toko yang sama akan tinggi dan akan mendorong pelanggan tersebut untuk melakukan pembelian kembali (online repurchase intention), karena pelanggan pernah memiliki pengalaman yang menyenangkan sebelumnya dan memiki peluang lebih besar untuk melakukan online repurchase intention di masa yang akan datang.

Perceived value adalah pengaruh positif yang signifikan terhadap online repurchase intention dengan nilai $t$-statistic di atas $1,96(>1,96)$ dan nilai $p$-value di bawah 0,05 ( < 0,05). Hasil penelitian ini juga relevan dengan penelitian yang dilakukan Chai Har Lee, Uchenna Cyril Eze, Nelson Oly Ndubisi (2010) juga mengatakan bahwa perceived value berpengaruh positif yang signifikan terhadap niat pembelian kembali online (online repurchase intention). Jika pelanggan mendapat produk sesuai dengan yang mereka inginkan, maka persepsi terhadap produk tersebut sudah terbentuk secara baik di mata pelanggan. Sehingga, peluang untuk kembali berbelanja pada toko yang sama lebih besar. Sebaliknya, pelanggan yang tidak mendapatkan produk sesuai keinginan mereka, maka persepsi buruk akan terbentuk dan peluang untuk kembali berbelanja di toko yang sama sangat kecil. Perilaku pembelian kembali didorong dengan adanya penilaian manfaat dan biaya yang keluarkan oleh pelanggan. Ketika pelanggan membeli sebuah pakaian pada toko online di Instagram, asumsi yang ada dipikiran pelanggan adalah bahwa produk pakaian yang dibeli dapat menjadi produk yang bermanfaat dan pelanggan merasakan kesenangan dari penggunaan produk tersebut. Sehingga penting bagi penjual pakaian pada toko online di Instagram untuk mengetahui keinginan pelanggan agar pelanggan dapat melakukan online repurchase intention.

Trust adalah pengaruh positif yang signifikan terhadap online repurchase intention dengan nilai $t$-statistic di atas $1,96(>1,96)$ dan nilai $p$-value di bawah $0,05(<0,05)$. Hasil 
penelitian ini relevan dengan penelitian yang dilakukan Chai Har Lee, Uchenna Cyril Eze, Nelson Oly Ndubisi (2010) juga mengatakan bahwa kepercayaan pelanggan berpengaruh positif yang signifikan terhadap niat pembelian kembali online (online repurchase intention). Jika tingkat kepercayaan pelanggan pada toko online di Instagram tinggi, maka kecendrungan pelanggaan untuk melakukan online repurchase intention juga tinggi. Kepercayaan pelanggan sangat perlu diperhatikan karena secara faktor psikologis kepercayaan sering kali dapat mengendalikan pikiran pelanggan dalam melakukan online repurchase intention. Jika kepercayaan yang diberikan oleh penjual pakaian pada toko online di Instagram kurang, maka hal tersebut akan berdampak pada pelanggan untuk tidak melakukan online repurchase intention. Seperti janji-janji yang telah dibuat oleh penjual pakaian pada toko online di Instagram benar dan ditepati, komunikasi antara penjual dengan pelanggan baik, dari hal-hal tersebut dapat mengurangi pertanyaan yang pada awalnya menjadi keraguan pelanggan berubah menjadi kepastian seperti yang diinginkan pelanggan sehingga kepercayaan pelanggan akan tinggi dan hal tersebut dapat menjadi pemicu dalam mengarahkan pelanggan untuk melakukan online repurchase intention.

\section{PENUTUP}

Penelitian ini membahas tentang pengaruh customer satisfaction, perceived value, dan trust terhadap online repurchase intention pada fashion di instagram di Jakarta. Berdasarkan hasil penelitian di atas, maka sebaiknya Penjual pakaian pada toko online di Instagram harus tetap mengutamakan kepuasan pelanggan atau dapat lebih ditingkatkan agar pelanggan percaya dan melakukan pembelian ulang. Karena, kepuasan pelanggan merupakan faktor paling besar yang mempengaruhi niat pembelian kembali online (online repurchase intention). Pihak penjual bisa memberikan hadiah atau free gift saat pelanggan melakukan pembelian ulang.Penjual pakaian pada toko online di Instagram juga harus memberikan kepercayaan (trust) yang tinggi agar pelanggan dapat melakukan online repurchase intention dengan memberikan manfaat dari produk yang dijual seperti kualitas pada produk dan sebagainya itu nyata. Sehingga pelanggan juga tidak merasa dibohongi oleh penjual. Pihak penjual dapat memberikan rasa aman dalam bertransaksi untuk pelanggan.

Diharapkan penelitian lainnya dapat meneliti variabel lain yang dapat memprediksi online repurchase intention sehingga variabel penelitian tidak selalu sama dan tidak terbatas, agar dapat dijadikan perbandingan penelitian ini dengan penelitian lainnya.

\section{DAFTAR PUSTAKA}

Chen, Y.S. (2010). The drivers of green brand equity: Green Brand Image, Green Satisfaction, and Green Trust. Journal of Business Ethics, 93(2), 307-319.

Chiu, C. M., Hsu, M. H., Lai, H., \& Chang, C. M. (2012). Re-examining the influence of trust on online repeat purchase intention: The moderating role of habit and its antecedents. Decision Support Systems, 53(4), 835-845.

Chiu, C.M., Linb, H.Y., Sunc, S.Y. and Hsu, M.-H. (2009). Understanding customers' loyalty intentions towards online shopping: an integration of technology acceptance model and fairness theory. Behaviour \& Information Technology, 28(4), 347-60 
Cronin, J. J., Brady, M. K., \& Hult, G.T. (2000). Assessing the effects of quality, value and customer satisfaction on consumer behavioral intentions in service environments. Journal of Retailing, 76, 193-218.

Gefen, D., Karahanna, E. \& Straub, D. W. (2003). Trust and TAM in Online Shopping: An Integrated Model. MIS Quarterly, 27(1), 51-90.

Ghozali, Imam (2014). Structural Equation Modeling, Metode Alternatif dengan Partial Least Square (PLS). (Edisi 4). Semarang: Badan Penerbit Universitas Diponegoro.

Grunert, K.G. and Ramus, K. (2005). Consumers' willingness to buy food through the internet. British Food Journal, 107(6), 381-403.

Hellier, Phillip K., Gus Geursen, Rodney A. Carr, and John A. Rickard (2003). Customer Repurchase Intention: A General Structural Equation Model. European Journal of Marketing, 37 (11/12), 1762- 1800.

Kotler, Philip (2008). Manajamen Pemasaran Alih Bahasa Benyamin. (Jilid 1 dan 2). Jakarta: PT. Indeks Kelompok Gramedia, 83.

Lee, Chai har, Eze, Uchenna Cyril and Ndubisi, Nelson Oly (2010). Analyzing key determinants of online repurchase intentions. Asia Pacific Journal of Marketing and Logistics, 23(2), 200-221.

Pavlou, P.A. and Fygenson, M. (2006). Understanding and predicting electronic commerce adoption: an extension of the theory of planned behaviour. MIS Quarterly, 30(1), 115143.

Phuong, N.N.C., \& Trang, T.T.D. (2018). Repurchase Intention: The Effect of Service Quality, System Quality, Information Quality, and Customer Satisfaction as Mediating Role: A PLS Approach of M-Commerce Ride Hailing Service in Vietnam. Marketing and Branding Research 5, 78-91.

Reichheld, F. F., \& Schefter, P. (2000). E-loyalty: Your secret weapon on the Web. Harvard Business Review, July-August, 105-13.

Zeithaml, V.A. (2000). Service Quality, Profitability, and The Economic Worth of Customers: What We Know and What We Need to Learn. Academy of Marketing Science Journal, 28(1), 67-85.

Zhao, G.M. (2010). Research on Customer Loyalty of B2C E-commerce. China-USA Business Review, 9(5), 46-52. 